\title{
Risk of moderate to advanced kidney disease in patients with psoriasis: population based cohort study

\author{
(C) $(\Theta \Theta$ OPEN ACCESS
}

\author{
Joy Wan resident physician ${ }^{1}$, Shuwei Wang predoctoral research fellow ${ }^{1}$, Kevin Haynes senior \\ research investigator ${ }^{2}$, Michelle R Denburg assistant professor of pediatrics ${ }^{3}$, Daniel B Shin \\ predoctoral research fellow ${ }^{12}$, Joel M Gelfand associate professor ${ }^{12}$
}

${ }^{1}$ Department of Dermatology, University of Pennsylvania, Philadelphia, PA 19104, USA; ${ }^{2}$ Center for Clinical Epidemiology and Biostatistics, University of Pennsylvania, Philadelphia, PA 19104, USA; ${ }^{3}$ Department of Nephrology, The Children's Hospital of Philadelphia, Philadelphia, PA 19104, USA

\begin{abstract}
Objective To determine the risk of chronic kidney disease in patients with psoriasis.

Design Population based cohort study and nested cross sectional study.

Setting Electronic medical records database based in United Kingdom.

Participants Cohort study: patients with psoriasis aged 18-90 each matched to up to five patients without psoriasis based on age, practice, and time of visit. Nested study: patients with psoriasis aged 25-64 with confirmed data on psoriasis severity, each matched to up to 10 patients without psoriasis based on age and practice.
\end{abstract}

Main outcome measures Cohort study: incident moderate to advanced (stage 3 through 5) chronic kidney disease. Nested study: baseline prevalence of chronic kidney disease.

Results 136529 patients with mild psoriasis and 7354 patients with severe psoriasis based on treatment patterns were matched to 689702 unaffected patients. The adjusted hazard ratios (95\% confidence intervals) for incident chronic kidney disease were 1.05 (1.02 to 1.07), 0.99 (0.97 to 1.02 ), and 1.93 (1.79 to 2.08 ) in the overall, mild, and severe psoriasis groups, respectively. Age was a significant effect modifier in the severe psoriasis group, with age specific adjusted hazard ratios (95\% confidence intervals) of 3.82 (3.15 to 4.64$)$ and 2.00 (1.86 to 2.17 ) for patients aged 30 and 60 , respectively. In the nested analysis of 8731 patients with psoriasis with measurements of affected body surface area matched to 87310 patients without psoriasis, the adjusted odds ratios (95\% confidence intervals) for chronic kidney disease were 0.89 (0.72 to 1.10$), 1.36$ (1.06 to 1.74 ), and 1.58 (1.07 to 2.34 ) in the mild, moderate, and severe psoriasis groups, respectively.

Conclusions Moderate to severe psoriasis is associated with an increased risk of chronic kidney disease independent of traditional risk factors.

\section{Introduction}

Psoriasis is a common chronic inflammatory disease of the skin and joints that has a peak onset in young adulthood and affects $2-4 \%$ of the general population. ${ }^{12}$ Increasing evidence suggests that psoriasis is associated with diabetes, metabolic syndrome, and cardiovascular disease, often independent of the traditional risk factors. ${ }^{13-6}$ Chronic inflammation driven by T cell activation and cytokines such as tumor necrosis factor $\alpha$ is thought to be the pathophysiologic link between psoriasis and these other systemic conditions. ${ }^{1}$ While the existence of a "psoriatic nephropathy" has been proposed based on case reports of glomerulonephritides in patients with psoriasis, ${ }^{7}$ the association between psoriasis and kidney disease remains largely unclear. Studies to date examining kidney disease in patients with psoriasis have primarily been cross sectional in design with small sample sizes and have yielded conflicting results. In a recent cross sectional study by Yang and colleagues, renal failure was more prevalent in patients with severe psoriasis than in age and sex matched controls (odds ratio $1.59,95 \%$ confidence interval 1.09 to 2.32 ). ${ }^{8}$ We previously conducted a population based cohort study examining cause specific mortality in people with psoriasis and found a fourfold increase in death from nephritic or non-hypertensive kidney disease among those with severe psoriasis. ${ }^{4}$ Multiple cross sectional studies have also observed greater prevalence of microalbuminuria, a sign of subclinical glomerular dysfunction, in patients with psoriasis. ${ }^{9-12}$ Yet other studies have detected no association between psoriasis and renal disease, including one prevalence study that found similar rates of renal failure among 753 patients with psoriasis compared with national estimates. ${ }^{13-15}$ Furthermore, these previous analyses often did not adjust for potential confounders such as diabetes, hypertension, and use of nephrotoxic drugs. ${ }^{89} 15$ 
We investigated the risk of chronic kidney disease in a broadly representative population based cohort of patients with psoriasis. We hypothesized that patients with psoriasis, especially if it is severe, have an increased risk of moderate to advanced (stage 3-5) chronic kidney disease compared with patients without psoriasis.

\section{Methods}

\section{Study design and data source}

We conducted a population based cohort study using The Health Improvement Network (THIN), an electronic medical records database maintained by general practitioners in the United Kingdom. THIN is broadly representative of the general UK population and contains diagnostic, treatment, and laboratory data on over nine million individuals. In the UK, almost all patients are registered with a general practitioner who serves as the primary contact for healthcare and records data on diagnoses, prescriptions, and laboratory results as part of the patient's electronic medical record. THIN has been widely used for epidemiological research and has been previously validated for the study of psoriasis, chronic kidney disease, and other diagnoses. ${ }^{16-18}$ Data in this study were collected prospectively from 2003 to September 2010. The study was conducted in accordance with the STROBE statement. ${ }^{19}$

\section{Study population, definitions of exposure and outcome, and follow-up}

We included in the study all patients with psoriasis aged 18-90 at their start date (defined below) with at least one day of observation time. THIN data are coded in Read codes, which are alphanumeric codes that group and define illnesses by using a hierarchical system. ${ }^{20}$ Patients with psoriasis were identified if they received a diagnostic Read code for psoriasis, as previously validated in THIN. ${ }^{17}$ Severe psoriasis was defined by the presence of a prescription code for treatments consistent with severe psoriasis on or after the diagnosis of psoriasis (such as phototherapy including ultraviolet $\mathrm{B}$ or psoralen and ultraviolet A (PUVA), methotrexate, azathioprine, cyclosporine, oral retinoids, hydroxyurea, mycophenolate mofetil, etanercept, adalimumab, infliximab, and ustekinumab). Patients without treatment codes for systemic or biologic treatment or phototherapy for psoriasis were classified as having mild disease.

Each patient with psoriasis was randomly matched with up to five unexposed patients (that is, no history of a diagnostic code for psoriasis) aged 18-90 whose ages were within five years of the exposed patient's age, who were seen in the same practice, and who had a date of observation within 180 days before or after the index date of the patient with psoriasis (defined below), thus ensuring that patients with and without psoriasis were followed up by the same practice during similar time periods. We excluded patients with diagnosis of chronic kidney disease before cohort entry.

Follow-up time began at the latest of the date when the patient's practice began recording information using THIN software, six months after the date of patient registration in the practice, and the date of psoriasis diagnosis for the exposed cohort or the closest corresponding visit for the unexposed cohort. Censoring occurred when patients developed chronic kidney disease, died, transferred out of the practice, or reached the end of the study.

The outcome of incident chronic kidney disease was defined as the patient receiving a diagnostic code or having an estimated glomerular filtration rate (eGFR) consistent with moderate to advanced (stage 3-5) chronic kidney disease, or both. We used serum creatinine data to calculate eGFR using the Modification of Diet in Renal Disease (MDRD) formula and following widely accepted classification guidelines for chronic kidney disease, which define moderate to severe chronic kidney disease as eGFR $<60 \mathrm{~mL} / \mathrm{min} / 1.73 \mathrm{~m}^{2}$ on at least two occasions more than 90 days apart. ${ }^{21-23}$ In the absence of complete laboratory data, we also used a list of 80 Read codes to identify moderate to advanced chronic kidney disease, a method that has been previously investigated within THIN. ${ }^{18}$ We also examined incident end stage renal disease (ESRD) as a secondary outcome, defined by a relevant diagnostic code for end stage renal disease or dialysis, or both. ${ }^{22}$

We recorded known risk factors for chronic kidney disease, such as age, sex, presence of diabetes, hypertension, and cardiovascular disease, and other potential confounders including use of non-steroidal anti-inflammatory drugs, hyperlipidemia, and body mass index (BMI). Patients were classified as having diabetes, hypertension, hyperlipidemia, and cardiovascular disease if they ever received a diagnostic code for these conditions before the start of the study. BMI, use of alcohol and non-steroidal anti-inflammatory drugs, and smoking status were determined from the recorded data closest to the start date.

All patients with psoriasis who met selection criteria were included in the study, yielding 143883 patients with psoriasis and 689702 without. Power calculations were made before data collection and were based on estimates of eligible patients within THIN. With 131490 patients with mild psoriasis, 3510 with severe psoriasis, and 540000 without psoriasis, we would have $80 \%$ power to detect a hazard ratio of 1.10 and 1.62 in the mild and severe psoriasis groups, respectively.

\section{Statistical analysis}

We examined the age, sex, person time, and covariate distribution between patients with mild and severe psoriasis and unexposed controls using $\chi^{2}$ and Fisher exact tests for categorical data and Mann-Whitney and $t$ tests for continuous variables. We compared the rates of chronic kidney disease in the mild and severe psoriasis groups versus unexposed groups with Cox proportional hazards regression. Adjustments were made for pertinent risk factors determined a priori such as age, sex, presence of hypertension, diabetes, or cardiovascular disease and BMI and use of non-steroidal anti-inflammatory drugs. As data on BMI were missing in $25 \%$ of patients, we performed multiple imputation as part of a sensitivity analysis. Smoking and alcohol use were excluded from the primary model as they are not confirmed risk factors for chronic kidney disease, though they were examined in sensitivity analyses. We also investigated interactions between age and psoriasis and between sex and psoriasis on the risk of chronic kidney disease. Log-log survival plots were examined for adequate proportionality.

We performed multiple sensitivity analyses to further assess the robustness of our results, such as excluding patients with psoriatic arthritis and patients with psoriasis treated with potentially nephrotoxic cyclosporine and methotrexate. We also adjusted for use of non-steroidal anti-inflammatory drugs during follow-up and excluded patients with rheumatoid arthritis and osteoarthritis given their propensity to use these drugs. To further ensure the validity of diabetes, hypertension, and hyperlipidemia covariates, we performed analyses requiring a prescription consistent with these diagnoses. In addition, we accounted for the time varying nature of risk factors such as diabetes. We also examined a stricter outcome definition of 
chronic kidney disease, defined as eGFR $<60 \mathrm{~mL} / \mathrm{min} / 1.73 \mathrm{~m}^{2}$ on at least two occasions more than 90 days apart and without any intervening or subsequent eGFR $\geq 90 \mathrm{~mL} / \mathrm{min} / 1.73 \mathrm{~m}^{2}$, and/or one of 45 diagnostic codes with known positive predictive values over $80 \%$ for chronic kidney disease. ${ }^{18}$ Lastly, to minimize screening bias, we conducted sensitivity analyses accounting for frequency of patient visits and/or contact with the healthcare system as well as frequency of serum creatinine screening.

All statistical analyses were performed with Stata (version 12, StataCorp, College Station, TX). Significance was determined by using two sided $\mathrm{P}$ values at $\mathrm{P}<0.05$.

\section{Nested cross sectional study}

To further evaluate the relation between chronic kidney disease and severity of psoriasis, as defined by direct measures of extent of disease rather than by use of treatment, we examined a subgroup of patients aged 25-64 whose severity of disease had been assessed via questionnaires sent to their general practitioners as part of a prospective cohort called the Incident Health Outcomes and Psoriasis Events $\left(\mathrm{iHOPE}^{24}\right.$ ) study. ${ }^{6}{ }^{17} \mathrm{In}$ the iHOPE cohort, eligible patients with psoriasis were randomly sampled within age categories from individuals with at least one diagnostic code for psoriasis within two years before the survey. Patients were defined as having psoriasis if their diagnosis was confirmed by their general practitioner in the questionnaire. Of 10474 eligible patients, their general practitioners completed 10026 mailed surveys $(95.7 \%$ response rate), confirming the diagnoses in 9056 (90.3\%) patients. General practitioners directly measured the extent of psoriasis and classified it as mild (limited disease with $\leq 2 \%$ body surface area (BSA) affected) in $4526(51.8 \%)$ patients, moderate (scattered disease with 3-10\% BSA) in 3123 (35.8\%) patients, and severe (extensive disease with $>10 \%$ BSA) in $1082(12.4 \%)$ patients. ${ }^{25}$ A simple categorized measurement of affected body surface area has previously shown excellent reliability and validity. ${ }^{26}$ Each patient with psoriasis was randomly matched to 10 control patients without psoriasis based on age category and medical practice. We conducted a cross sectional analysis of baseline data in the Incident Health Outcomes and Psoriasis Events cohort, performing conditional logistic regression to examine the prevalence odds ratios of chronic kidney disease in patients with psoriasis versus matched controls with respect to measured disease severity.

\section{Results}

We identified 143883 patients with psoriasis (136 529 with mild disease and 7354 with severe disease based on treatment patterns) and 689702 matched patients without psoriasis. Although patients with psoriasis were statistically more likely to be male and older, the distribution of these variables was generally similar between people with and without psoriasis (table $1 \Downarrow$ ). Patients with psoriasis were more likely to have diabetes, hypertension, cardiovascular disease, and higher BMI than people without psoriasis, consistent with previous studies. ${ }^{127}$ Among patients with severe psoriasis based on treatment history, 67\% (4956) were treated with methotrexate (table $2 \Downarrow$ ).

Patients with psoriasis, particularly those with severe disease based on treatment history, had a higher incidence of chronic kidney disease compared with control patients (table $3 \Downarrow$ ). In unadjusted models, the relative risk of incident chronic kidney disease was increased among all patients with psoriasis (hazard ratio $1.13,95 \%$ confidence interval 1.11 to 1.15 ), with patients with severe psoriasis having the highest relative risk (hazards ratios were 1.08 (1.05 to 1.10$)$ and 1.90 (1.78 to 2.04 ) in patients with mild and severe psoriasis, respectively). After adjustment for sex, age, cardiovascular disease, diabetes, hypertension, hyperlipidemia, use of non-steroidal anti-inflammatory drugs, and BMI, however, psoriasis remained an independent risk factor for chronic kidney disease in the severe psoriasis group but its effect was attenuated in the overall group because of loss of significance in the mild psoriasis group (table $3 \Downarrow$ ). Though there was no interaction between sex and psoriasis, age was a significant effect modifier in the severe psoriasis group (table 3 ), indicating that the relative risk of chronic kidney disease is highest in younger patients (fig $1 \Downarrow$ ). For example, in patients with severe psoriasis, the relative risk of developing chronic kidney disease is 3.82 (3.15 to 4.64) in a 30 year old but 2.00 ( 1.86 to 2.17 ) in a 60 year old. Nevertheless, the adjusted attributable risk of chronic kidney disease due to psoriasis still increases with age because the baseline risk of chronic kidney disease increases with age (table $4 \Downarrow$ ). Similar to findings for chronic kidney disease, the relative risk of incident end stage renal disease was significantly increased only among patients with severe psoriasis (adjusted hazard ratio 4.15, 1.70 to 10.11). There was no significant interaction between age and psoriasis on the development of incident end stage renal disease (table $3 \Downarrow)$. These results were robust to multiple sensitivity analyses (table $5 \Downarrow$ ).

In a nested analysis comparing 8731 psoriasis patients with measurements of disease extent (body surface area affected) and 87310 matched controls, there was a dose-response effect in the prevalence of chronic kidney disease with respect to severity of psoriasis. In models fully adjusted for age, sex, cardiovascular disease, diabetes, hypertension, hyperlipidemia, BMI, use of non-steroidal anti-inflammatory drugs, and duration of observation, the odds ratios of chronic kidney disease were 0.89 (95\% confidence interval 0.72 to 1.10 ), 1.36 (1.06 to 1.74 ), and 1.58 (1.07 to 2.34) among patients with mild, moderate, and severe disease, respectively (fig $2 \Downarrow$ ). The adjusted prevalence odds ratios of chronic kidney disease in patients with psoriasis of less than two years' duration and 10 or more years' duration were 0.90 (0.64 to 1.28 ) and 1.24 (1.01 to 1.53 ), respectively. These findings remained robust to multiple sensitivity analyses (data not shown), although results were attenuated in the analyses in which we excluded patients with severe psoriasis (more than 10\% of the body surface area affected) who had received methotrexate or cyclosporine $(24 \%$ of patients with severe psoriasis).

\section{Discussion Principal findings}

To our knowledge this is the first population based cohort study to compare the incidence of moderate to advanced chronic kidney disease in patients with and without psoriasis, thus providing generalizability and allowing us to assess the temporal relation between psoriasis and chronic kidney disease. We found that severe psoriasis, defined by treatment patterns, is an independent risk factor for moderate to advanced chronic kidney disease. These findings were confirmed when we evaluated the prevalence of chronic kidney disease based on severity of psoriasis as determined by the general practitioner's categorization of affected body surface area. The combined results indicate that, although no association is seen in patients with truly mild disease (less than $2 \%$ body surface area affected), as consistent with previous studies, associations are seen in moderate and severe psoriasis, which are estimated to affect over $20 \%$ of patients with psoriasis worldwide. ${ }^{28}$ The relative risk of chronic kidney disease is especially increased in younger 
patients, similar to previous findings for myocardial infarction in psoriasis. ${ }^{3}$ Nevertheless, despite attenuation of the association with increasing age, the clinical relevance of the absolute risk of chronic kidney disease attributable to psoriasis increases with age. In patients aged 40-50 with severe disease based on treatment patterns, psoriasis accounts for one extra case of chronic kidney disease per 134 patients per year, and in those aged 50-60, it accounts for one additional case per 62 patients per year.

\section{Comparison with other studies}

Our results are consistent with previous descriptive work showing a higher prevalence of renal failure in patients with severe psoriasis. ${ }^{84}$ The increased relative risk of end stage renal disease among patients with severe psoriasis also fits with earlier findings of increased renal related mortality in those individuals. ${ }^{4}$ Furthermore, most previous studies evaluating renal disease in patients with psoriasis have focused on indicators of subclinical glomerular dysfunction, such as urinary albumin excretion..$^{9-12} 15$ Although these markers can be used to predict nephropathy, they might not indicate the presence of or subsequent progression to severe renal insufficiency. Moreover, studies examining these markers have had mixed results, with a handful of studies failing to find any differences in urinary albumin excretion or creatinine clearance between patients with psoriasis and healthy individuals. ${ }^{14}{ }^{15}$ These null findings might have been caused by small sample sizes, but it is also possible that patients with and without psoriasis differ not with respect to subclinical glomerular dysfunction but rather in the eventual development of moderate to advanced renal insufficiency, as assessed in this study.

\section{Strengths and limitations of study}

We adjusted for confounders such as diabetes, hypertension, and use of nephrotoxic drugs, factors that had served as exclusion criteria or were altogether not evaluated in previous studies. ${ }^{8}{ }^{15}$ Our results suggest that there is an association between psoriasis and chronic kidney disease independent of comorbidities in psoriasis, such as diabetes and cardiovascular disease. Furthermore, we found that the association between severe psoriasis and renal insufficiency is not driven by joint disease or associated use of nephrotoxic drugs. Sensitivity analyses excluding patients with psoriatic arthritis, rheumatoid arthritis, or osteoarthritis showed results similar to the primary model. Our findings also remained robust when we adjusted for frequency of use of non-steroidal anti-inflammatory drugs both at baseline and averaged over follow-up. As cyclosporine and methotrexate can induce nephrotoxicity, ${ }^{28-30}$ we conducted sensitivity analyses excluding patients who used these drugs and found that the higher relative risk of chronic kidney disease persisted among patients with severe psoriasis who had not received cyclosporine or methotrexate. Lastly, to ensure that we were capturing incident and not prevalent chronic kidney disease, we performed additional analyses restricted to patients who had received a diagnosis of chronic kidney disease at least one year after their start date and found similar results.

While moderate to advanced chronic kidney disease is a distinct outcome, its development stems from a heterogeneous group of kidney diseases. The mechanisms mediating renal injury in psoriasis remain thus unclear. Numerous case reports have described the coexistence of psoriasis and glomerulonephritis, most commonly IgA nephropathy, focal segmental glomerulosclerosis, and membranous nephropathy, ${ }^{91-35}$ suggesting that immunologic mechanisms such as defects in $\mathrm{T}$ cell function and increased levels of immune complexes underlie glomerular injury in psoriasis. ${ }^{7}{ }^{36}$ On the other hand, tubular injury induced by raised uric acid concentrations in people with psoriasis is another theoretical mechanism. ${ }^{37}$ Examination of specific renal diseases is warranted to better characterize renal insufficiency among patients with psoriasis.

As with all studies, there are important limitations to consider. First, misclassification bias is possible when systemic treatments are used as a marker of severity of psoriasis. As direct measurements of the extent of psoriasis are not encoded within THIN, the identification of severe disease was based on treatment patterns. Nevertheless, use of treatments as a proxy measure of severity has been widely accepted. ${ }^{3}{ }^{38}{ }^{39}$ Direct measurements of the extent of body surface area affected by psoriasis were also examined in the nested analysis, which corroborated our primary findings. As azathioprine can be prescribed for other dermatologic disorders such as eczema and use of phototherapy can indicate acute flares rather than chronic severe psoriasis, we also performed sensitivity analyses excluding patients who received these treatments and found results consistent with the primary analysis. Notably, the prevalence of biologic therapy in our cohort was low, probably because most biologics are exclusively prescribed by specialists and thus might not be fully captured in THIN. Moreover, biologic therapy did not become prevalent for psoriasis treatment in the UK until after $2005 .{ }^{40}$ While outcome misclassification is also a potential limitation, particularly in database studies, the practitioners collecting THIN data were unaware of the hypotheses being tested, and thus any bias would probably be non-differential and bias findings towards the null. Our outcome is further strengthened by our use of the standard laboratory based definition of chronic kidney disease in addition to diagnostic codes, thereby minimizing misclassification. It is worth noting, however, that current definitions of chronic kidney disease are controversial, and some researchers argue that they lead to the overdiagnosis of subclinical chronic kidney disease. ${ }^{41}$ Nevertheless, this potentially increased capture of chronic kidney disease is likely non-differential between patients with and without psoriasis. Furthermore, we performed sensitivity analyses examining each specific stage within moderate to severe chronic kidney disease and observed an increased risk across all severities of renal dysfunction among patients with psoriasis. Our finding of an association between psoriasis and dialysis dependent end stage renal disease further argues that the association between psoriasis and chronic kidney disease is not driven solely by the overdiagnosis of subclinical renal impairment.

Second, it is conceivable that patients with psoriasis might visit their physicians more often or are screened earlier and more often for chronic kidney disease, thus leading to ascertainment bias. End stage renal disease, an outcome more robust to screening bias, however, was also significantly associated with severe psoriasis and argues against ascertainment bias, supporting our results for chronic kidney disease. In other words, even if mild renal disease were more likely to be detected because of increased surveillance among patients with psoriasis, dialysis dependent renal disease should present clinically, regardless of screening frequency. We also performed sensitivity analyses restricted to patients with similar frequencies of screening for chronic kidney disease or contact with the healthcare system and found similar results. Third, unmeasured and unknown confounders could exist, though we accounted for all major confounders in our primary analysis as well as many other possible confounders in sensitivity analyses. Lastly, The Health Improvement Network does not contain data on race, which could lead to underestimation of renal function 
among black patients as the MDRD formula for estimating glomerular filtration rate from serum creatinine involves a correction factor for black race. This inherent limitation to The Health Improvement Network data cannot be overcome and was unlikely to impact our results as only an estimated $3 \%$ of the UK population is black. ${ }^{42}$

\section{Conclusions and policy implications}

In conclusion, moderate to severe psoriasis is associated with moderate to advanced chronic kidney disease independent of traditional risk factors. Closer monitoring for renal insufficiency, such as routine screening urinalysis for microalbuminuria and serum creatinine and blood urea nitrogen testing, should be considered for patients with psoriasis affecting $3 \%$ or more of the body surface area. Increased screening efforts will allow for earlier detection and intervention to reduce the substantial morbidity and mortality associated with chronic kidney disease. Additionally, the risk versus benefit of potentially nephrotoxic drugs in patients with moderate to severe psoriasis should be carefully considered. Future studies are warranted to confirm our findings, determine the mechanisms mediating renal insufficiency in psoriasis, and examine the impact of treatment for psoriasis on the risk of chronic kidney disease.

Contributors: All authors participated in the study design and statistical analysis planning. JW, MRD, and JMG were responsible for study conception, JW, KH, and DBS for data collection and management, JW, SW, and DBS for statistical analysis, and JW for the manuscript draft. All authors reviewed the data and analysis, revised the manuscript, had full access to all of the data in the study and can take responsibility for the integrity of the data and the accuracy of the data analysis, and had authority over approval of final manuscript version and the decision to submit for publication. JMG, SW, JW, and DBS are guarantors.

Funding: This study was supported by grants from the National Institute of Arthritis and Musculoskeletal and Skin Diseases K24AR064310 (JMG) and training grant T32-AR07465 (SW), the National Heart, Lung, and Blood Institute R01-HL089744 (JMG), and the National Institute of Diabetes and Digestive and Kidney Diseases K23-DK093556 (MRD) and training grant T35-DK060441 (JW) and UL1TR000003 (KH). Funding sources had no role in the study, and researchers were independent from funders.

Competing interests: All authors have completed the ICMJE uniform disclosure form at www.icmje.org/coi_disclosure.pdf and declare: MRD has received research grants from the NephCure Foundation-American Society of Nephrology and the National Kidney Foundation/Amgen KDOQI research fellowship; JMG has received research grants from Amgen, Abbvie, Eli Lilly, and Novartis and honorariums from Abbvie, Jansen, Novartis, Eli Lilly, and Pfizer; JMG chairs the data and safety monitoring boards for Celgene and Merck.

Ethical approval: The study protocol was reviewed and approved by the University of Pennsylvania institutional review board and the scientific review committee of The Health Improvement Network.

Data sharing: Relevant statistical code available on request from the corresponding author.

Griffiths CE, Barker JN. Pathogenesis and clinical features of psoriasis. Lancet 2007;370:263-71.

2 Kurd SK, Gelfand JM. The prevalence of previously diagnosed and undiagnosed psoriasis in US adults: results from NHANES 2003-2004. J Am Acad Dermatol 2009;60:218-24.

3 Gelfand JM, Neimann AL, Shin DB, Wang X, Margolis DJ, Troxel AB. Risk of myocardial infarction in patients with psoriasis. JAMA 2006;296:1735-41.

4 Abuabara K, Azfar RS, Shin DB, Neimann AL, Troxel AB, Gelfand JM. Cause-specific mortality in patients with severe psoriasis: a population-based cohort study in the U.K. Br J Dermatol 2010;163:586-92.

5 Azfar RS, Seminara NM, Shin DB, Troxel AB, Margolis DJ, Gelfand JM. Increased risk of diabetes mellitus and likelihood of receiving diabetes mellitus treatment in patients with psoriasis. Arch Dermatol 2012;148:995-1000.
6 Langan SM, Seminara NM, Shin DB, Troxel AB, Kimmel SE, Mehta NN, et al. Prevalence of metabolic syndrome in patients with psoriasis: a population-based study in the United Kingdom. J Invest Dermatol 2012;132:556-62.

7 Singh NP, Prakash A, Kubba S, Ganguli A, Singh AK, Sikdar S, et al. Psoriatic nephropathy—does an entity exist? Ren Fail 2005;27:123-7.

8 Yang YW, Keller JJ, Lin HC. Medical comorbidity associated with psoriasis in adults: a population-based study. Br J Dermatol 2011;165:1037-43.

9 Dervisoglu E, Akturk AS, Yildiz K, Kiran R, Yilmaz A. The spectrum of renal abnormalities in patients with psoriasis. Int Urol Nephrol 2012;44:509-14.

10 Szepietowski JC, Bielicka E, Wasik F, Kopec W, Szepietowski T. Microalbuminuria as a subclinical marker of renal impairment in subjects with psoriasis vulgaris. J Eur Acad Dermatol Venereol 2000;14:513-4

11 Cecchi R, Seghieri G, Gironi A, Tuci F, Giomi A. Relation between urinary albumin excretion and skin involvement in patients with psoriasis. Dermatology 1992;185:93-5.

12 Madeddu P, Ena P, Glorioso N, Cerimele D, Rappelli A. High prevalence of microproteinuria, an early index of renal impairment, in patients with diffuse psoriasis. Nephron 1988;48:222-5.

13 Pearce DJ, Morrison AE, Higgins KB, Crane MM, Balkrishnan R, Fleischer AB Jr, et al. The comorbid state of psoriasis patients in a university dermatology practice. J Dermatolog Treat 2005:16:319-23.

14 Kaftan O, Kaftan B, Toppare MF, Eksioglu M. Renal involvement in psoriasis. Dermatology 1996;192:189-90.

15 Cassano N, Vestita M, Panaro M, Carbonara M, Vena GA. Renal function in psoriasis patients. Eur J Dermatol 2011;21:264-5.

16 Lewis JD, Schinnar R, Bilker WB, Wang X, Strom BL. Validation studies of the health improvement network (THIN) database for pharmacoepidemiology research. Pharmacoepidemiol Drug Saf 2007;16:393-401.

17 Seminara NM, Abuabara K, Shin DB, Langan SM, Kimmel SE, Margolis D, et al. Validity of The Health Improvement Network (THIN) for the study of psoriasis. Br J Dermatol 2011;164:602-9.

18 Denburg M, Haynes K, Shults J, Lewis J, Leonard MB. Validation of the Health Improvement Network (THIN) database for epidemiologic studies of chronic kidney disease. Pharmacoepidemiol Drug Saf 2010;19:\$105.

19 von Elm E, Altman DG, Egger M, Pocock SJ, Gotzsche PC, Vandenbroucke JP. The Strengthening the Reporting of Observational Studies in Epidemiology (STROBE) statement: guidelines for reporting observational studies. Lancet 2007;370:1453-7.

20 Booth N. What are the Read Codes? Health Libr Rev 1994;11:177-82.

21 Levey AS, Bosch JP, Lewis JB, Greene T, Rogers N, Roth D. A more accurate method to estimate glomerular filtration rate from serum creatinine: a new prediction equation. Modification of Diet in Renal Disease Study Group. Ann Intern Med 1999;130:461-70.

$22 \mathrm{~K} / \mathrm{DOQ}$ clinical practice guidelines for chronic kidney disease: evaluation, classification, and stratification. Am J Kidney Dis 2002;39(2 suppl 1):S1-266.

23 Archibald G, Bartlett W, Brown A, Christie B, Elliott A, Griffith K, et al. UK Consensus Conference on Early Chronic Kidney Disease-6 and 7 February 2007. Nephrol Dial Transplant 2007:22:2455-7.

24 Yeung H, Takeshita J, Mehta NN, Kimmel SE, Ogdie A, Margolis DJ, et al. Psoriasis severity and the prevalence of major medical comorbidity: a population-based Study. JAMA Dermatol 2013; Aug 7, doi:10.1001/jamadermatol.2013.5015.

25 The psoriasis and psoriatic arthritis pocket guide: treatment algorithms and management options. National Psoriasis Foundation, 2006. www.psoriasis.org/document.doc?id=354

6 Dommasch ED, Shin DB, Troxel AB, Margolis DJ, Gelfand JM. Reliability, validity and responsiveness to change of the Patient Report of Extent of Psoriasis Involvement (PREPI) for measuring body surface area affected by psoriasis. Br J Dermatol 2010;162:835-42.

27 Kimball AB, Gladman D, Gelfand JM, Gordon K, Horn EJ, Korman NJ, et al. National Psoriasis Foundation clinical consensus on psoriasis comorbidities and recommendations for screening. J Am Acad Dermatol 2008;58:1031-42.

28 Perazella MA, Moeckel GW. Nephrotoxicity from chemotherapeutic agents: clinical manifestations, pathobiology, and prevention/therapy. Semin Nephrol 2010;30:570-81.

29 Widemann BC, Adamson PC. Understanding and managing methotrexate nephrotoxicity. The oncologist 2006;11:694-703

30 Naesens M, Kuypers DR, Sarwal M. Calcineurin inhibitor nephrotoxicity. Clin J Am Soc Nephrol 2009:4:481-508.

31 Imai H, Kodama T, Ishino T, Yasuda T, Miura AB, Asakura K, et al. IgA nephropathy associated with hyper IgAnemia, psoriasis or pustulosis and ossification. Clin Nephrol 1995;44:64-8.

32 Zadrazil J, Tichy T, Horak P, Nikorjakova I, Zima P, Krejci K, et al. IgA nephropathy associated with psoriasis vulgaris: a contribution to the entity of 'psoriatic nephropathy'. J Nephrol 2006;19:382-6.

33 Ahuja TS, Funtanilla M, de Groot JJ, Velasco A, Badalamenti J, Wilson S. IgA nephropathy in psoriasis. Am J Nephrol 1998;18:425-9.

34 Kaji T, Tsukada Y, Shimada A, Miyamoto K, Yoshida M, Yano S, et al. Membranous nephropathy associated with psoriasis vulgaris. Clin Nephrol 1994;42:63-4.

35 Sirolli V, Bonomini M. Glomerulopathies associated with psoriasis: a report of three cases. Nephron 2000;86:89-90

$36 \mathrm{Kim} \mathrm{M}, \mathrm{Ko} \mathrm{Y}$, Yeo UC, Kim Y, Oh H. Psoriasis and glomerulonephritis. Clin Exp Dermatol 1998;23:295-6.

37 Bruce IN, Schentag CT, Gladman DD. Hyperuricemia in psoriatic arthritis: prevalence and associated features. J Clin Rheumatol 2000;6:6-9.

38 Brauchli YB, Jick SS, Miret M, Meier CR. Psoriasis and risk of incident myocardial infarction, stroke or transient ischaemic attack: an inception cohort study with a nested case-control analysis. Br J Dermatol 2009;160:1048-56.

39 Mehta NN, Azfar RS, Shin DB, Neimann AL, Troxel AB, Gelfand JM. Patients with severe psoriasis are at increased risk of cardiovascular mortality: cohort study using the General Practice Research Database. Eur Heart J 2010;31:1000-6.

40 Smith CH, Anstey AV, Barker JN, Burden AD, Chalmers RJ, Chandler D, et al. British Association of Dermatologists guidelines for use of biological interventions in psoriasis 2005. Br J Dermatol 2005;153:486-97.

41 Moynihan R, Glassock R, Doust J. Chronic kidney disease controversy: how expanding definitions are unnecessarily labelling many people as diseased. BMJ 2013;347:f4298.

42 Office for National Statistics. Population estimates by ethnic group 2002-2009. Statistics Bulletin, May 2011.

Accepted: 07 September 2013 


\section{What is already known on this topic}

Psoriasis has been associated with other systemic inflammatory conditions including diabetes, metabolic syndrome, and cardiovascular disease

Glomerulonephritides observed in patients with psoriasis have led to the proposal of a "psoriatic nephropathy," though studies examining renal disease in patients with psoriasis have thus far been limited and had conflicting results

\section{What this study adds}

Moderate to severe psoriasis is associated with moderate to advanced chronic kidney disease independent of traditional risk factors for renal dysfunction

Closer monitoring for renal insufficiency should be considered for patients with moderate to severe psoriasis (those with $3 \%$ or more body surface area affected), and nephrotoxic drugs should used with caution in this at risk population

\section{Cite this as: BMJ 2013;347:f5961}

This is an Open Access article distributed in accordance with the Creative Commons Attribution Non Commercial (CC BY-NC 3.0) license, which permits others to distribute, remix, adapt, build upon this work non-commercially, and license their derivative works on different terms, provided the original work is properly cited and the use is non-commercial. See: http://creativecommons.org/licenses/by-nc/3.0/. 


\section{Tables}

Table 1/ Characteristics of patients with psoriasis in study of risk of chronic kidney disease. Figures are numbers (percentage) unless stated otherwise

\begin{tabular}{|c|c|c|c|c|c|c|c|c|c|}
\hline & \multicolumn{3}{|c|}{ All psoriasis } & \multicolumn{3}{|c|}{ Mild psoriasis } & \multicolumn{3}{|c|}{ Severe psoriasis } \\
\hline & $\begin{array}{c}\text { Controls } \\
(n=689702)\end{array}$ & $\begin{array}{l}\text { Patients } \\
\text { (n=143 883) }\end{array}$ & P value ${ }^{*}$ & $\begin{array}{c}\text { Controls } \\
(n=654210)\end{array}$ & $\begin{array}{c}\text { Patients } \\
(n=136529)\end{array}$ & P value* & $\begin{array}{l}\text { Controls } \\
(n=35 \text { 492) }\end{array}$ & $\begin{array}{l}\text { Patients } \\
(n=7354)\end{array}$ & $P$ value $^{*}$ \\
\hline Men & 311618 (45) & 70655 (49) & $<0.001$ & 295641 (45) & $66988(49)$ & $<0.001$ & $15977(45)$ & $3667(50)$ & $<0.001$ \\
\hline $\begin{array}{l}\text { Median (IQR) age } \\
\text { at start of follow-up } \\
\text { (years) }\end{array}$ & $44(32-58)$ & $45(32-59)$ & $<0.001 \dagger$ & $43(32-58)$ & $44(32-59)$ & $<0.001 \dagger$ & $47(36-58)$ & $47(36-59)$ & $0.004 \dagger$ \\
\hline Diabetes mellitus & 25903 (4) & $6027(4)$ & $<0.001$ & 24550 (4) & $5624(4)$ & $<0.001$ & $1353(4)$ & $403(5)$ & $<0.001$ \\
\hline Hypertension & $90488(13)$ & $20293(14)$ & $<0.001$ & $85642(13)$ & $19123(14)$ & $<0.001$ & $4846(14)$ & $1170(16)$ & $<0.001$ \\
\hline $\begin{array}{l}\text { Cardiovascular } \\
\text { disease } \neq\end{array}$ & 45725 (7) & $10976(8)$ & $<0.001$ & $43312(7)$ & $10408(8)$ & $<0.001$ & $2413(7)$ & $568(8)$ & 0.01 \\
\hline Hyperlipidemia & $39321(6)$ & $8966(6)$ & $<0.001$ & $37160(6)$ & $8480(6)$ & $<0.001$ & $2161(6)$ & $486(7)$ & 0.09 \\
\hline Psoriatic arthritis & - & $8290(6)$ & NA & - & $5220(4)$ & NA & - & $3070(42)$ & NA \\
\hline Mean (SD) BMI§ & $25.9(5.3)$ & $26.4(5.5)$ & $<0.001 \rrbracket$ & $25.9(5.3)$ & $26.4(5.4)$ & $<0.001 \rrbracket$ & $26.1(5.3)$ & $27.4(5.7)$ & $<0.0019$ \\
\hline \multicolumn{10}{|l|}{ NSAID use ${ }^{\star *}$ : } \\
\hline Never & $346612(50)$ & $76960(53)$ & $<0.001$ & 328587 (50) & $74127(54)$ & $<0.001$ & $18025(51)$ & $2833(39)$ & $<0.001$ \\
\hline Past & 201521 (29) & $33870(24)$ & - & $191396(29)$ & $32398(24)$ & - & $10125(28)$ & $1472(20)$ & - \\
\hline $\begin{array}{l}\text { Current (<2 } \\
\text { prescriptions/year) }\end{array}$ & 64391 (9) & 12875 (9) & - & $61140(9)$ & $12103(9)$ & - & 3251 (9) & $772(11)$ & - \\
\hline $\begin{array}{c}\text { Current (2-5 } \\
\text { prescriptions/year) }\end{array}$ & 37468 (5) & $9522(7)$ & - & 35424 (5) & $8584(6)$ & - & $2044(6)$ & $938(13)$ & - \\
\hline $\begin{array}{c}\text { Current }(\geq 5 \\
\text { prescriptions/year) }\end{array}$ & $39710(6)$ & $10656(7)$ & - & $37663(6)$ & $9317(7)$ & - & 2047 (6) & $1339(18)$ & - \\
\hline \multicolumn{10}{|c|}{ Reason for censorship: } \\
\hline Death & $33045(5)$ & $8027(6)$ & $<0.001$ & $31313(5)$ & $7572(6)$ & $<0.001$ & $1732(5)$ & $455(6)$ & $<0.001$ \\
\hline $\begin{array}{l}\text { Transfer from } \\
\text { practice }\end{array}$ & $159118(23)$ & $34903(24)$ & - & $151114(23)$ & $33898(25)$ & - & $8004(23)$ & $1005(14)$ & - \\
\hline End of follow-up & $497539(72)$ & $100953(70)$ & - & $471783(72)$ & $95059(70)$ & - & $25756(73)$ & $5894(80)$ & - \\
\hline
\end{tabular}

IQR=interquartile range; $\mathrm{SD}=$ standard deviation; NSAID=non-steroidal anti-inflammatory drugs; NA=not applicable.

${ }^{*} \chi^{2}$ test.

†Rank sum test.

‡Includes coronary artery disease, history of myocardial infarction, congestive heart failure, peripheral arterial disease, stroke, and transient ischemic attack.

§Data on BMI missing in 202043 (24.24\%) patients (168 469 (24.43\%) controls; 33574 (23.33\%) patients with psoriasis).

I $t$ test

${ }^{* *}$ Never (no NSAID prescription ever), past (last NSAID prescription over 365 days before index date), recent (last NSAID prescription within 365 days before index date, further subdivided by number of prescriptions over past 365 days). 
Table 2| Systemic treatments for psoriasis received by 7354 patients with severe psoriasis*

\begin{tabular}{lc} 
Treatment & No (\%) \\
Phototherapy $†$ & $1185(16)$ \\
\hline Systemic oral: & $6371(87)$ \\
\hline Any & $4956(67)$ \\
\hline Methotrexate & $760(10)$ \\
\hline Azathioprine & $733(10)$ \\
\hline Cyclosporine & $346(5)$ \\
\hline Oral retinoidsł & $231(3)$ \\
\hline Hydroxyurea & $91(1)$ \\
\hline Mycophenolate mofetil & $26(<1)$ \\
\hline Tacrolimus & \\
\hline Biologic therapy: & $48(<1)$ \\
\hline Any & $23(<1)$ \\
\hline Etanercept & $18(<1)$ \\
\hline Adalimumab & $7(<1)$ \\
\hline Infliximab & 0 \\
\hline Efalizumab & 0 \\
\hline Ustekinumab &
\end{tabular}

*Percentages might not total 100 as patients can have received multiple treatments. †Includes psoralen and ultraviolet therapies.

łIncluding acitretin, etretinate. 


\begin{tabular}{|c|c|c|c|c|c|c|}
\hline \multirow[b]{2}{*}{ Variable } & \multicolumn{2}{|c|}{ All psoriasis } & \multicolumn{2}{|c|}{ Mild psoriasis } & \multicolumn{2}{|c|}{ Severe psoriasis } \\
\hline & $\begin{array}{c}\text { Controls }(n=689 \\
702)\end{array}$ & $\begin{array}{c}\text { Patients }(n=143 \\
883)\end{array}$ & $\begin{array}{c}\text { Controls }(n=654 \\
210)\end{array}$ & $\begin{array}{c}\text { Patients }(n=136 \\
529)\end{array}$ & $\begin{array}{c}\text { Controls }(n=35 \\
492)\end{array}$ & Patients $(n=7354)$ \\
\hline \multicolumn{7}{|c|}{ Follow-up time (years): } \\
\hline Mean (SD) & $5.38(3.99)$ & $5.23(3.94)$ & $5.33(3.98)$ & $5.16(3.93)$ & $6.25(4.07)$ & $6.40(4.00)$ \\
\hline Median (IQR) & 4.52 (1.98 to 8.47$)$ & 4.28 (1.89 to 8.22$)$ & 4.46 (1.94 to 8.41$)$ & $4.20(1.86$ to 8.11$)$ & 5.79 (2.78 to 9.45$)$ & 5.98 (2.98 to 9.48$)$ \\
\hline No of person years & 3708255 & 751825 & 3486541 & 704732 & 221714 & 47092 \\
\hline $\begin{array}{l}\text { No }(\%) \text { of new } \\
\text { cases of CKD }\end{array}$ & $50206(7)$ & $11483(8)$ & $47204(7)$ & $10268(8)$ & $3002(9)$ & $1215(17)$ \\
\hline $\begin{array}{l}\text { Incidence per } 1000 \\
\text { person years }(95 \% \\
\mathrm{Cl})\end{array}$ & $\begin{array}{c}13.54(13.42 \text { to } \\
13.66)\end{array}$ & $\begin{array}{c}15.27(15.00 \text { to } \\
15.56)\end{array}$ & $\begin{array}{c}13.54(13.42 \text { to } \\
13.66)\end{array}$ & $\begin{array}{c}14.57(14.29 \text { to } \\
14.85)\end{array}$ & $\begin{array}{c}13.54(13.06 \text { to } \\
14.03)\end{array}$ & $\begin{array}{c}25.80(24.39 \text { to } \\
27.29)\end{array}$ \\
\hline \multicolumn{7}{|c|}{ Hazard ratio $(95 \% \mathrm{Cl})$ for incident CKD: } \\
\hline Unadjusted & 1 (ref) & $1.13(1.11$ to 1.15$)$ & 1 (ref) & $1.08(1.05$ to 1.10$)$ & 1 (ref) & 1.90 (1.78 to 2.04$)$ \\
\hline Adjusted $^{*}$ & 1 (ref) & $1.05(1.02$ to 1.07$)$ & 1 (ref) & $0.99(0.97$ to 1.02$)$ & 1 (ref) & $1.93(1.79$ to 2.08$)$ \\
\hline \multicolumn{7}{|c|}{ Hazard ratio $(95 \% \mathrm{Cl})$ for incident ESRD } \\
\hline Unadjusted & 1 (ref) & 1.25 (0.96 to 1.65$)$ & 1 (ref) & $1.08(0.80$ to 1.46$)$ & 1 (ref) & 3.59 (1.73 to 7.46$)$ \\
\hline Adjusted* $^{*}$ & 1 (ref) & $1.15(0.84$ to 1.58$)$ & 1 (ref) & $0.98(0.69$ to 1.38$)$ & 1 (ref) & $4.15(1.70$ to 10.11$)$ \\
\hline
\end{tabular}

$\mathrm{SD}=$ standard deviation; IQR=interquartile range; $\mathrm{ESRD}=$ end stage renal disease.

*Adjusted for sex, age, cardiovascular disease, diabetes mellitus, hyperlipidemia, hypertension, use of non-steroidal anti-inflammatory drugs, BMI (body mass index). 
Table 4| Risk of chronic kidney disease (CKD) attributable to severe psoriasis by age*

\begin{tabular}{lcc} 
& \multicolumn{2}{c}{ Risk of chronic kidney disease (95\% Cl) } \\
\cline { 2 - 3 } Age range (years) & Attributable risk (per $\mathbf{1 0 0 0}$ person years) & Excess risk (case per No of patients per year) \\
$20-30$ & $1.17(0.87$ to 5.30$)$ & $1 / 855$ (646 to 1153$)$ \\
\hline $30-40$ & $2.89(2.26$ to 3.64$)$ & $1 / 346(275$ to 443$)$ \\
\hline $40-50$ & $7.48(6.15$ to 8.97$)$ & $1 / 134(112$ to 163$)$ \\
\hline $50-60$ & $16.21(13.84$ to 18.80$)$ & $1 / 62(54$ to 73$)$ \\
\hline $60-70$ & $27.93(23.11$ to 33.15$)$ & $1 / 36(31$ to 44$)$ \\
\hline $70-80$ & $31.44(20.89$ to 43.23$)$ & $1 / 32(24$ to 48$)$
\end{tabular}

*Attributable and excess risks calculated at median age within each age group by using adjusted hazard ratios for CKD in patients with severe psoriasis and incidence of CKD in unexposed patients. 
Table 5| Sensitivity analyses for relation between psoriasis and chronic kidney disease (CKD). Figures are hazard ratios (95\% confidence intervals) by age

\begin{tabular}{|c|c|c|c|c|c|c|}
\hline & \multicolumn{2}{|c|}{ Psoriasis overall } & \multicolumn{2}{|c|}{ Mild psoriasis } & \multicolumn{2}{|c|}{ Severe psoriasis } \\
\hline & Age 30 & Age 60 & Age 30 & Age 60 & Age 30 & Age 60 \\
\hline Primary model ${ }^{*}$ & 1.20 (1.13 to 1.29$)$ & 1.07 (1.04 to 1.10$)$ & $\begin{array}{c}1.02(0.95 \text { to } \\
1.10)\end{array}$ & $\begin{array}{c}1.00(0.97 \text { to } \\
1.02)\end{array}$ & $3.82(3.15$ to 4.64$)$ & 2.00 (1.86 to 2.17$)$ \\
\hline $\begin{array}{l}\text { Excluding patients with } \\
\text { psoriatic arthritis }\end{array}$ & 1.10 (1.02 to 1.18$)$ & $\begin{array}{c}1.03(1.002 \text { to } \\
1.06)\end{array}$ & $\begin{array}{c}1.01(0.93 \text { to } \\
1.08)\end{array}$ & $\begin{array}{c}0.99(0.96 \text { to } \\
1.02)\end{array}$ & 3.09 (2.39 to 3.99$)$ & 1.79 (1.62 to 1.97$)$ \\
\hline $\begin{array}{l}\text { Excluding patients treated } \\
\text { with cyclosporine and/or } \\
\text { methotrexate }\end{array}$ & 1.05 (0.98 to 1.13$)$ & 1.01 (0.98 to 1.04$)$ & NA & NA & 2.89 (1.94 to 4.31$)$ & 1.74 (1.49 to 2.03 ) \\
\hline $\begin{array}{l}\text { Excluding patients treated } \\
\text { with azathioprine }\end{array}$ & $1.18(1.10$ to 1.26$)$ & 1.06 (1.03 to 1.09$)$ & NA & NA & 3.65 (2.97 to 4.49$)$ & 1.98 (1.82 to 2.15$)$ \\
\hline $\begin{array}{l}\text { Excluding patients treated } \\
\text { with phototherapy }\end{array}$ & 1.20 (1.12 to 1.28$)$ & 1.07 (1.04 to 1.09$)$ & NA & NA & 4.31 (3.50 to 5.31$)$ & 2.11 (1.94 to 2.28 ) \\
\hline $\begin{array}{l}\text { Excluding patients with } \\
\text { rheumatoid arthritis and/or } \\
\text { osteoarthritis }\end{array}$ & 1.27 (1.18 to 1.37$)$ & 1.07 (1.04 to 1.10$)$ & $\begin{array}{c}1.09(1.003 \text { to } \\
1.18)\end{array}$ & $\begin{array}{c}1.00(0.97 \text { to } \\
1.03)\end{array}$ & 4.16 (3.32 to 5.22$)$ & 2.02 (1.84 to 2.22 ) \\
\hline $\begin{array}{l}\text { Primary model also adjusted } \\
\text { for average NSAID use during } \\
\text { follow-up (No of prescriptions } \\
\text { per year) }\end{array}$ & $1.20(1.13$ to 1.28$)$ & 1.07 (1.04 to 1.10$)$ & $\begin{array}{c}1.02(0.95 \text { to } \\
1.10)\end{array}$ & $\begin{array}{c}1.00(0.97 \text { to } \\
1.02)\end{array}$ & 3.59 (2.95 to 4.36$)$ & 1.95 ( 1.81 to 2.11$)$ \\
\hline $\begin{array}{l}\text { Primary model also adjusted } \\
\text { for alcohol use and smoking } \\
\text { status }\end{array}$ & 1.18 (1.10 to 1.27$)$ & 1.06 (1.04 to 1.09$)$ & $\begin{array}{c}1.01(0.94 \text { to } \\
1.09)\end{array}$ & $\begin{array}{c}0.99(0.97 \text { to } \\
1.02)\end{array}$ & 3.69 (3.00 to 4.53$)$ & 1.93 (1.78 to 2.09 ) \\
\hline $\begin{array}{l}\text { Using multiple imputation for } \\
\text { missing BMI data }\end{array}$ & $1.22(1.15$ to 1.29$)$ & 1.07 (1.05 to 1.09$)$ & $\begin{array}{c}1.04(0.98 \text { to } \\
1.11)\end{array}$ & $\begin{array}{c}1.00(0.97 \text { to } \\
1.02)\end{array}$ & 3.55 (3.00 to 4.21$)$ & 1.97 (1.84 to 2.11$)$ \\
\hline $\begin{array}{l}\text { Redefining covariatest to } \\
\text { require prescription consistent } \\
\text { with diagnosis }\end{array}$ & $1.20(1.13$ to 1.29$)$ & 1.07 (1.04 to 1.10$)$ & $\begin{array}{c}1.02(0.95 \text { to } \\
1.10)\end{array}$ & $\begin{array}{c}1.00(0.97 \text { to } \\
1.02)\end{array}$ & 3.84 (3.16 to 4.66$)$ & 2.00 (1.85 to 2.16$)$ \\
\hline $\begin{array}{l}\text { Using strict CKD code and/or } \\
\text { lab outcome }\end{array}$ & 1.19 (1.11 to 1.28$)$ & 1.06 (1.03 to 1.09$)$ & $\begin{array}{c}1.03(0.95 \text { to } \\
1.10)\end{array}$ & $\begin{array}{c}1.00(0.97 \text { to } \\
1.02)\end{array}$ & 3.56 (2.91 to 4.36$)$ & 1.86 (1.72 to 2.01$)$ \\
\hline $\begin{array}{l}\text { Redefining incident CKD } \\
\text { outcome as diagnosis } \\
\text { occurring } \geq 1 \text { year after start } \\
\text { date }\end{array}$ & 1.21 (1.13 to 1.30$)$ & 1.05 (1.02 to 1.08$)$ & $\begin{array}{c}1.03(0.95 \text { to } \\
1.11)\end{array}$ & $\begin{array}{c}0.98(0.95 \text { to } \\
1.01)\end{array}$ & 3.95 (3.20 to 4.87$)$ & 1.90 (1.75 to 2.07$)$ \\
\hline \multicolumn{7}{|c|}{ Using only lab based KDOQI definition of moderate to advanced CKD: } \\
\hline Stages 3-5 combined & $1.21(1.13$ to 1.29$)$ & 1.07 (1.04 to 1.10$)$ & $\begin{array}{c}1.01(0.94 \text { to } \\
1.09)\end{array}$ & $\begin{array}{c}0.99(0.96 \text { to } \\
1.02)\end{array}$ & 3.84 (3.14 to 4.70$)$ & 2.07 (1.91 to 2.24$)$ \\
\hline Stage 3 & $1.21(1.13$ to 1.29$)$ & 1.07 (1.04 to 1.10$)$ & $\begin{array}{c}1.02(0.94 \text { to } \\
1.10)\end{array}$ & $\begin{array}{c}0.99(0.96 \text { to } \\
1.02)\end{array}$ & 3.77 (3.08 to 4.62$)$ & 2.07 (1.91 to 2.24$)$ \\
\hline Stage 4 & $\begin{array}{c}1.44(1.004 \text { to } \\
2.06)\end{array}$ & $1.16(1.02$ to 1.31$)$ & $\begin{array}{c}1.06(0.71 \text { to } \\
1.57)\end{array}$ & $\begin{array}{c}1.04(0.91 \text { to } \\
1.20)\end{array}$ & $\begin{array}{c}9.54(3.57 \text { to } \\
25.45)\end{array}$ & 2.12 (1.46 to 3.08$)$ \\
\hline Stage 5 & 0.97 (0.46 to 2.02$)$ & 0.99 (0.74 to 1.33$)$ & $\begin{array}{c}0.60(0.25 \text { to } \\
1.41)\end{array}$ & $\begin{array}{c}0.85(0.61 \text { to } \\
1.18)\end{array}$ & $\begin{array}{c}11.28(1.66 \text { to } \\
6.75)\end{array}$ & $2.32(0.95$ to 5.66$)$ \\
\hline $\begin{array}{l}\text { Restricting to patients who } \\
\text { were seen on average at least } \\
\text { once a year in } 5 \text { years before } \\
\text { follow-up }\end{array}$ & $1.22(1.14$ to 1.31$)$ & $1.10(1.07$ to 1.13$)$ & $\begin{array}{c}1.04(0.96 \text { to } \\
1.12)\end{array}$ & $\begin{array}{c}1.02(0.99 \text { to } \\
1.05)\end{array}$ & 3.80 (3.08 to 4.68$)$ & 2.04 (1.88 to 2.22$)$ \\
\hline $\begin{array}{l}\text { Restricting to patients with } \geq 1 \\
\text { serum creatinine } \\
\text { measurement in } 5 \text { years } \\
\text { before follow-up }\end{array}$ & $1.64(1.35$ to 2.00$)$ & $1.32(1.23$ to 1.41$)$ & $\begin{array}{c}1.42(1.15 \text { to } \\
1.76)\end{array}$ & $\begin{array}{c}1.23(1.14 \text { to } \\
1.33)\end{array}$ & $3.31(1.81$ to 6.04$)$ & 2.27 (1.83 to 2.81$)$ \\
\hline $\begin{array}{l}\text { Using time varying } \\
\text { covariates } \ddagger\end{array}$ & $1.19(1.11$ to 1.28$)$ & 1.06 (1.03 to 1.09$)$ & $\begin{array}{c}1.01(0.93 \text { to } \\
1.08)\end{array}$ & $\begin{array}{c}0.98 \text { (0.96 to } \\
1.01)\end{array}$ & 3.86 (3.06 to 4.70$)$ & 2.00 (1.86 to 2.17$)$ \\
\hline
\end{tabular}

$\mathrm{NSAID}=$ non-steroidal anti-inflammatory drugs; $\mathrm{BMI}=$ body mass index; $\mathrm{NA}=$ not applicable.

*Adjusted for sex, age, cardiovascular disease, diabetes, hyperlipidemia, hypertension, NSAID use, BMI, age $\times$ psoriasis interaction

†Diabetes, hypertension, hyperlipidaemia.

$\ddagger$ Cardiovascular disease, diabetes, hypertension, hyperlipidemia 


\section{Figures}

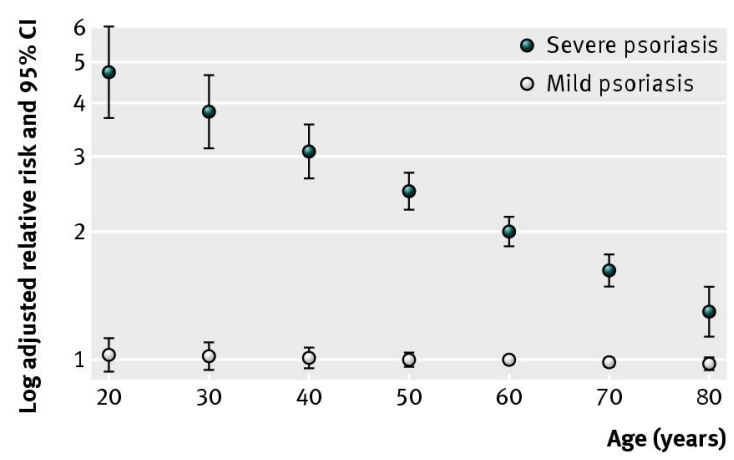

Fig 1 Adjusted relative risk of chronic kidney disease in patients with psoriasis based on patient age

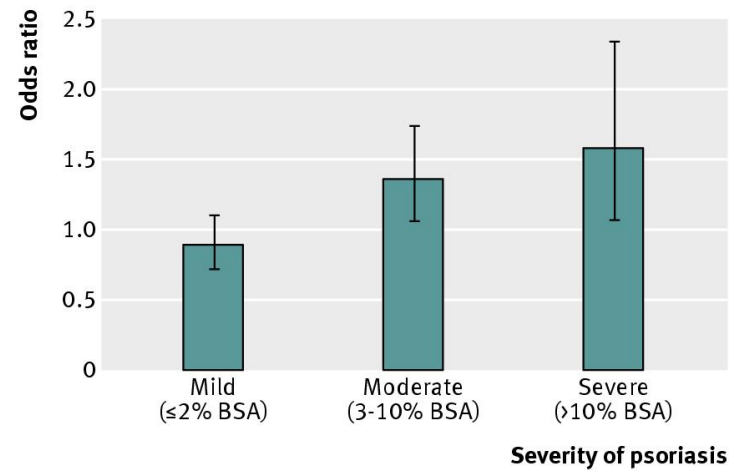

Fig 2 Adjusted prevalence odds ratio of chronic kidney disease in patients with psoriasis based on severity according to \% body surface area (BSA) affected 